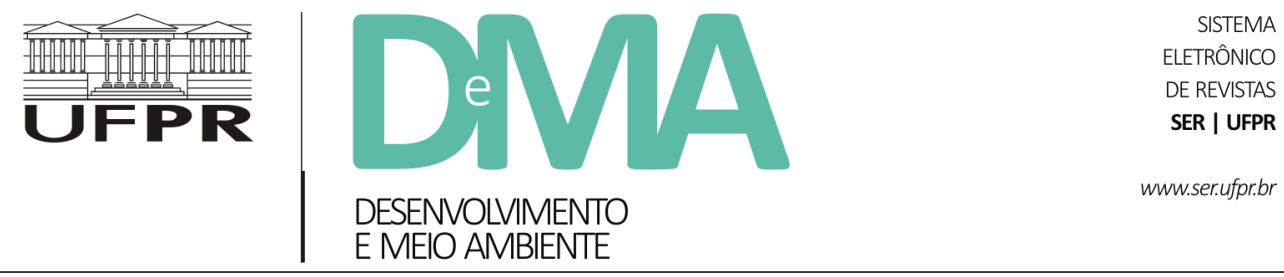

\title{
Licenciamentos ambientais de grandes empreendimentos: tendência à judicialização?
}

\section{Environmental licensing of large projects of infrastructure: is there a tendency towards judicialization?}

\author{
Victor Caldas Ferreira de CARVALHO ${ }^{1}$, Gabriela Marques Di GIULIO ${ }^{1 *}$ \\ ${ }^{1}$ Faculdade de Saúde Pública (FSP), Universidade de São Paulo (USP), São Paulo, SP, Brasil. \\ *E-mail de contato: ggiulio@usp.br
}

Artigo recebido em 11 de abril de 2017, versão final aceita em 17 de janeiro de 2018.

RESUMO: Os licenciamentos ambientais no Brasil, particularmente os que envolvem grandes empreendimentos de infraestrutura e diversidade de atores e interesses, como o setor modal portuário, têm ganhado os holofotes públicos e midiáticos, tendo em vista as disputas travadas nesses processos e os conflitos e as contradições que emergem destes. Como consequência dessa complexidade, muitas decisões sobre a concessão ou não das licenças, embora originalmente endereçadas a apenas um órgão ambiental do Poder Executivo, são submetidas ao crivo judicial. Essa complexidade é explorada neste artigo, que traz resultados de um estudo sobre a judicialização do licenciamento da expansão do Porto Público de São Sebastião, litoral norte de São Paulo. O artigo retoma a cronologia do conflito que emerge desse processo e discute um conjunto de variáveis críticas que pesaram na judicialização do licenciamento do porto. Argumentamos que, para além das causas explícitas nas ações judiciais, outras variáveis - as chamadas causas implícitas da judicialização permearam a dinâmica político-social que levou o conflito para o Poder Judiciário. Argumentamos ainda que a identificação dessas causas expõe as raízes das limitações que o licenciamento ambiental enfrenta na prática.

Palavras-chave: licenciamento ambiental; judicialização; Porto de São Sebastião; conflito socioambiental.

ABSTRACT: Environmental licensing processes in Brazil have received increasing attention from the media and the public, particularly those that involve large projects of infrastructure, a range of actors and diverse interests (i.e. port sector). These processes are in general characterized by disputes, conflicts and contradictions. Due to this complexity, many decisions about concessions of licensing have been submitted to the juridical sphere. This paper explores this complexity and brings results from a study that sought to investigate the judicialization of licensing to expand the Port of São Sebastião, North Coast of São Paulo State, Brazil. In this paper we present 
the conflict around this issue and its chronology, as well as discuss a set of critical variables that influenced the judicialization process. We argue that, beyond those officially declared causes for judicialization, other variables intersected with the political and social dynamic had lead this conflict to the Judiciary system. Identifying these non-official causes is especially critical to understand limitations and barriers of environmental licensing processes.

Keywords: environmental licensing; judicialization; Port of São Sebastião; socioenvironmental conflict.

\section{Introdução}

Nos últimos anos, os licenciamentos ambientais no Brasil vêm atraindo a atenção da sociedade e dos meios de comunicação, particularmente os que envolvem grandes empreendimentos de infraestrutura e diversidade de atores - empreendedor, órgão licenciador, Ministério Público, secretarias estaduais e municipais, organizações ambientalistas, associações de bairro, movimentos sindicais, comunidade científica e mídia. Além da multiplicidade de interesses, as disputas nos licenciamentos não se restringem apenas às que opõem defensores do meio ambiente e defensores do desenvolvimento econômico; por vezes, os conflitos e as contradições surgem em uma mesma instituição, suscitando questões políticas, econômicas e fundiárias (Christmann, 2012; Feital, 2014; Viglio, 2012; Teixeira, 2013). Como consequência dessa complexidade, muitas decisões sobre a concessão ou não das licenças, embora originalmente endereçadas a apenas um órgão ambiental do Poder Executivo, também acabam submetidas ao crivo judicial.
Tomando como referência um setor específico de infraestrutura no Brasil (o modal portuário), uma consulta a sites de órgãos públicos, como o Instituto Brasileiro do Meio Ambiente e dos Recursos Naturais Renováveis (IBAMA), o Ministério Público Federal, a Advocacia-Geral da União e o Poder Judiciário Federal, revela a tendência de judicialização dos licenciamentos ambientais. Entre as licenças ambientais emitidas pelo IBAMA no período de janeiro de 2013 a maio de 2016, por exemplo, foram localizados pelo menos 25 empreendimentos portuários ${ }^{1}$ com licenças disponíveis no cadastro virtual do órgão ambiental. Os sistemas de andamento processual dos sítios do Poder Judiciário e as páginas de notícias do Ministério Público Federal, por sua vez, mostraram que aproximadamente $50 \%$ desses licenciamentos estavam - ou já estiveram - sub judice ${ }^{2}$. A mesma consulta às bases de dados virtuais de órgãos públicos apontou que não existe uma concentração regional das ações judiciais, as iniciativas estão espraiadas por diversos Estados da Federação. Apesar do crescente número de processos abertos na última década, alguns tramitam há mais de 15

\footnotetext{
${ }^{1}$ A pesquisa na base de dados considerou os licenciamentos de construção e ampliação de portos ou terminais portuários, mas excluiu licenciamentos de regularização de portos em funcionamento ou obras meramente acessórias à atividade portuária, como dragagem, atracadouro, base de dutos e terminais de contêineres.

${ }^{2}$ Entre os empreendimentos que tiveram seus licenciamentos judicializados, estão o Terminal Marítimo de Alemoa, o Terminal Portuário do Paraná, o Canal Galheta, o Porto de Pecém, o Terminal Marítimo Mar Azul, o Terminal Portuário EMBRAPORT, o Porto de São Sebastião, o Terminal Santa Catarina (TESC), o Porto Sul, o Terminal Portuário da BTP, o Terminal Portuário Brites e o Porto de São Francisco do Sul.
} 
anos, evidenciando que a judicialização não é um fenômeno recente. Além disso, em quase todos os processos, é possível observar o papel protagonista do Ministério Público como autor das ações contra licenciamentos portuários (Carvalho, 2016).

Nessas obras de infraestrutura, os interesses do Estado brasileiro no licenciamento ambiental são os mais diversos. Com frequência, o empreendedor portuário é a própria Administração Pública Direta, ou uma autarquia, empresa pública ou sociedade de economia mista. Quem decide sobre a liberação das obras é o próprio Estado, por meio de um órgão ambiental licenciador. Diante dessa realidade, não raro se configura o autolicenciamento, situação em que o Estado analisa a autorização de atividades que ele mesmo propõe.

Em licenciamentos portuários, mesmo quando o empreendedor é uma empresa privada sem vínculos diretos com pessoas jurídicas de direito público, a União sempre terá interesses contratuais subjacentes, pois compete a ela, conforme estabelecido na Constituição Federal, explorar diretamente, ou mediante contratos de concessão, os portos marítimos, fluviais ou lacustres. Afora os interesses da União como poder concedente da administração portuária, a implementação de um empreendimento desse tipo é resultado de políticas públicas nas áreas de transportes e comércio internacional, visto que é de responsabilidade governamental o planejamento integrado dos modais logísticos, incluindo o portuário (Teixeira, 2013). Também não podem ser desprezados os interesses econômicos de estados e municípios onde o empreendimento será instalado, uma vez que a geração de empregos e o incremento da arrecadação fiscal estão entre os impactos que os estudos desses licenciamentos costumam citar como positivos. Por outro lado, aos impactos ambientais e diretos no local das obras, somam-se os impactos sociais e indiretos impostos à região de inserção do empreendimento. Com a indução de fluxos migratórios temporários ou definitivos, a instalação de grandes empreendimentos pode exercer pressão sobre o saneamento básico, a mobilidade urbana, o abastecimento hídrico, a política criminal, o controle do uso e a ocupação do solo, entre outras questões de saúde pública (Christmann, 2012; Feital, 2014; Viglio, 2012, Teixeira, 2013; Renk, 2010).

Os interesses públicos e as demandas se refletem na representação institucional dos principais atores que participam dos licenciamentos ambientais. Se, por um lado, o Estado - entendido como órgãos e entidades da Administração Pública Direta e Indireta - não é o único interessado, por outro seu papel multifacetado o coloca em uma posição de destaque perante os demais atores. Conflitos em torno de licenciamentos, judicializados ou não, nascem, desenvolvem-se e se resolvem, quase sempre, no âmbito estatal. Porém, essa concentração de poderes não necessariamente desestimula a atuação da sociedade. Pelo contrário, em algumas regiões do país, nota-se o aumento de atores não governamentais reivindicando maior participação e influência (Feital, 2014; Viglio, 2012). São grupos sociais que não integram as estruturas formais de poder; contudo, cada vez mais pressionam o governo a relevar seus interesses nas tomadas de decisão.

Essa complexidade é explorada neste artigo, que traz resultados de uma pesquisa desenvolvida entre 2014 e 2016, a qual buscou compreender as relações entre Estado e sociedade nos licenciamentos ambientais de infraestrutura, com base no estudo de caso da judicialização do licenciamento da expansão do Porto Público de São Sebastião, município localizado no litoral norte de São Paulo. 
Com base no entendimento de que os licenciamentos ambientais de grandes empreendimentos podem ser compreendidos como arenas (Renn, 1992; Hannigan, 2006; Ferreira et al., 2017; Feital, 2014) - uma vez que são espaços políticos em que se desvelam conflitos cercados de diversos atores, interesses e vieses -, este artigo retoma, por meio da análise de dados obtidos em pesquisa documental e da realização de entrevistas semiestruturadas com representantes das instituições que figuraram como autoras e rés das ações judiciais no caso estudado, a cronologia do conflito que emerge desse processo e discute um conjunto de variáveis críticas que pesaram na judicialização do licenciamento do porto. Argumentamos que, para além das causas explícitas nas ações judiciais, outras variáveis - as chamadas causas implícitas da judicialização - permearam a dinâmica político-social que levou o conflito para o Poder Judiciário. Argumentamos ainda que a identificação dessas causas expõe as raízes das limitações que o licenciamento ambiental (Brasil, 1997) enfrenta na prática.

O artigo está estruturado em quatro seções, para além desta Introdução. Na próxima seção, apresentamos os aspectos metodológicos da pesquisa realizada. Em seguida, exploramos a proposta de ampliação portuária e o conflito que emergiu dessa situação. Partimos, então, para a seção de resultados, os quais são discutidos com base na literatura consultada e em três eixos analíticos, que sustentam as causas implícitas da judicialização: (i) interesses e impactos sociais e ambientais relacionados ao empreendimento; (ii) entraves à negociação; e (iii) crise de identidade do instrumento legal do licen- ciamento ambiental. Finalmente, nas conclusões, refletimos, fundamentados no caso estudado, sobre a aparente dualidade da judicialização, compreendida ora como problema, ora como solução.

\section{Aspectos metodológicos}

O estudo realizado envolveu pesquisa documental, incluindo análise de notícias jornalísticas sobre a expansão do Porto de São Sebastião acessadas em páginas virtuais, consultas a licenças e pareceres do processo administrativo de licenciamento ambiental e informações lançadas nas duas ações judiciais referentes ao processo ${ }^{3}$. A análise do material documental foi feita por meio da análise de conteúdo, que visa selecionar, de maneira objetiva, panorâmica e qualitativa, o conteúdo manifesto em comunicação (Bardin, 1977). Como alertam Deacon et al. (1998), ao adotar a análise de conteúdo como técnica metodológica, é preciso definir questões que norteiam a análise do material documental obtido. Nesse sentido, a análise buscou identificar os posicionamentos dos principais atores sociais envolvidos na judicialização do licenciamento ambiental, suas estratégias de interação e comunicação, bem como os argumentos lançados para contestar o licenciamento ambiental e influenciar o processo.

O estudo realizado lançou mão também de pesquisas de campo, incluindo visitas ao município de São Sebastião e realização de entrevistas semiestruturadas (Deacon et al., 1998) com representantes das instituições envolvidas no conflito em torno da expansão do porto, as quais figuraram

\footnotetext{
${ }^{3}$ Ação Civil Pública n. 0000398-59.2014.4.03.6135 movida pelo Ministério Público Federal e Estadual em face do IBAMA e da Companhia Docas de São Sebastião (CDSS), que tramitou na $1^{\text {a }}$ Vara da Subseção Judiciária de Caraguatatuba, Estado de São Paulo, e com sentença transitada em julgado. Disponível em: <http://www.jfsp.jus.br/foruns-federais/>.
} 
como autoras e rés das ações judiciais. O critério de seleção dos entrevistados foi orientado pela principal indagação da pesquisa: Por que a judicialização? Assim, priorizou-se ouvir quem deu causa imediata aos processos judiciais, ou seja, os demandantes (autores) e demandados (réus). Foram entrevistados representantes de duas organizações não governamentais (ONGs) que, juntas, propuseram o primeiro processo judicial, um promotor de justiça do Estado de São Paulo (responsável pela segunda ação), um representante da empreendedora (a Companhia Docas de São Sebastião - CDSS) e dois representantes do IBAMA regional (órgão licenciador). A Tabela 1 sintetiza as informações sobre os entrevistados da pesquisa.

As entrevistas foram gravadas e os fragmentos foram analisados a partir de unidades de significação (Duarte, 2004).

\section{A proposta de ampliação portuária e o conflito que emerge}

As duas últimas décadas têm sido acompanhadas por intensas transformações sociais, econômicas e ambientais no litoral norte paulista (Feital, 2014; Teixeira, 2013; Viglio, 2012), particularmente com o crescimento expressivo de atividades relacionadas ao segmento de petróleo e gás. Contudo, no caso da expansão do Porto de São Sebastião, as primeiras movimentações para a ampliação portuária foram registradas ainda na década de 1950. Quatro décadas depois, já no final dos anos de 1990, a Secretaria de Transportes do Estado de São Paulo formulou um Plano Diretor de Desenvolvimento dos Transportes (PDDT), projetando, para o horizonte de 2000 a 2020, a construção de um segundo berço no Porto

TABELA 1 - Atores sociais entrevistados.

\begin{tabular}{|c|c|}
\hline $\begin{array}{l}\text { Movimento ambientalista (autor da primeira ação } \\
\text { judicial) }\end{array}$ & $\begin{array}{l}\text { - Representante do Instituto Ilhabela Sustentável } \\
\text { - Secretário de Meio Ambiente do município de } \\
\text { São Sebastião, representante do Instituto Educa } \\
\text { Brasil à época que essa ONG propôs a ação contra } \\
\text { o porto }\end{array}$ \\
\hline $\begin{array}{l}\text { Ministério Público (autor da segunda ação judi- } \\
\text { cial) }\end{array}$ & $\begin{array}{l}\text { - Promotor de justiça do Estado de São Paulo, } \\
\text { lotado no Grupo de Atuação de Defesa Especial do } \\
\text { Meio Ambiente - Gaema - do litoral norte paulista }\end{array}$ \\
\hline $\begin{array}{l}\text { Órgão federal responsável pela análise das licen- } \\
\text { ças ambientais (réu nas duas ações judiciais) }\end{array}$ & $\begin{array}{l}\text { - Dois representantes do IBAMA regional de } \\
\text { Caraguatatuba, litoral norte do Estado de São } \\
\text { Paulo, que prestam suporte técnico à Diretoria de } \\
\text { Licenciamento de Portos, instalada no escritório } \\
\text { do IBAMA, em Brasília }\end{array}$ \\
\hline
\end{tabular}

Empreendedor e proponente do licenciamento ambiental (réu nas duas ações judiciais)
- Representante da Companhia Docas do Estado de São Paulo

FONTE: Elaboração dos autores, adaptado de Carvalho (2016). 
Público de São Sebastião, além de investimentos em terminais, pátios e armazéns.

Em agosto de 2007, o Estado de São Paulo criou uma sociedade de economia mista - a Companhia Docas de São Sebastião (CDSS) -, com a finalidade específica de modernizar e desenvolver o porto. Em setembro de 2009, essa empresa estatal protocolou o Estudo de Impacto Ambiental (EIA) do Plano Integrado Porto-Cidade, formalizando a dimensão da expansão. A CDSS propôs converter o porto atual em um porto multiuso, mediante implantação de novos píeres que, ao avançarem sobre o canal marítimo de São Sebastião, permitiriam a operação de navios com calados de até 25 metros. O porto poderia, então, receber embarcações de última geração, incluindo navios de contêineres para o transporte de 9 mil TEUs (acrônimo do termo em inglês twenty-foot equivalent unit), medida internacional equivalente a um contêiner de 20 pés ou quase 7 metros (CPEA, 2011).

Além da ampliação aquaviária, a CDSS pleiteou o aumento de sua atual retroárea (área adjacente ao porto organizado, destinada a suprir as deficiências de área de armazenagem de cargas e desembaraço aduaneiro). A solução do empreendedor para aumentar a retroárea foi a incorporação de parte da enseada do Araçá, localizada ao sul das instalações hoje existentes. No Relatório de Impacto Ambiental (RIA) do Plano Integrado Porto-Cidade (CPEA, 2011), já se previa a construção de uma laje de concreto, apoiada em estacas, sobre 75\% da enseada do Araçá, de maneira a evitar seu aterramento. Segundo a empreendedora, o projeto de estaqueamento sobre a enseada preservaria a ilhota de Pernambuco, o mangue do Araçá, o mangue da balsa e o espelho d'água de acesso aos pescadores até a praia do Araçá. A cobertura da laje foi prevista para ocorrer ao longo de quatro fases, distribuídas no período de quase duas décadas, o que, de acordo com a CDSS, permitiria que as obras de ampliação acompanhassem a real demanda de cargas no futuro e a evolução das obras nas rodovias de acesso ao porto (CPEA, 2011).

As justificativas do Estado de São Paulo para aumentar o Porto de São Sebastião se relacionam tanto à tentativa de torná-lo uma base de apoio para as atividades de exploração off shore na contígua Bacia de Santos (CPEA, 2011) quanto à criação de um corredor de exportação para a movimentação de cargas sólidas no continente. Por isso, a solicitação pela CDSS de licenciamento ambiental do porto de cargas condiciona sua ampliação à melhoria das principais rodovias que dão acesso ao litoral norte paulista. A Figura 1 mostra a localização do Porto de São Sebastião.

\subsection{O início do conflito}

Na cronologia do conflito em torno da expansão portuária, é possível citar alguns marcos relevantes. Em setembro de 2009, a CDSS protocolou a versão inicial do EIA, formalizando ao IBAMA a real dimensão de sua intenção de ampliação portuária. Dois meses depois, uma audiência pública ocorria na Assembleia Legislativa do Estado de São Paulo para discutir a obra. Não era a audiência que a legislação prevê no curso do licenciamento ambiental, mas uma iniciativa espontânea promovida pela Comissão de Defesa do Meio Ambiente dos Deputados da Assembleia Legislativa. Em notícia divulgada no site dessa Casa Legislativa ${ }^{4}$, é possível

${ }^{4}$ http://www.al.sp.gov.br/noticia/?id=280083 
observar as divergências entre os participantes da audiência: de um lado, apontamentos sobre a viabilidade ambiental do empreendimento, defendida pela CDSS; de outro, representantes do poder público e de entidades da sociedade, que levantavam dúvidas quanto ao modelo de expansão proposto. Entre aqueles que questionavam a reforma portuária, estavam dois atores relevantes: o Instituto Educa Brasil, organização não governamental que depois se tornaria autora da primeira ação judicial contra o licenciamento, e o Instituto Ilhabela Sustentável, que se tornaria coautor da mesma ação.

Desde o início, a sociedade organizou movimentos, como o "Porto Sim, Mas Sem Contêiner" e o "Porto no Araçá, Não!", além de manifestações populares nas ruas e no canal marítimo, usando a internet para comunicar e mobilizar o público. Algumas comunidades surgiram em redes sociais e serviram como plataforma de informações, de debates, e como canais difusores da agenda dos protestos em locais públicos. Petições circularam na internet como forma de persuadir as autoridades a abandonar a ideia de expandir o porto (Carvalho, 2016).

A cronologia do conflito evidencia que a comunicação entre os atores se desenvolveu mais na esfera protocolar. Em janeiro de 2010, por exemplo, foi aberto, pelo Ministério Público Federal de Caraguatatuba, o inquérito civil público

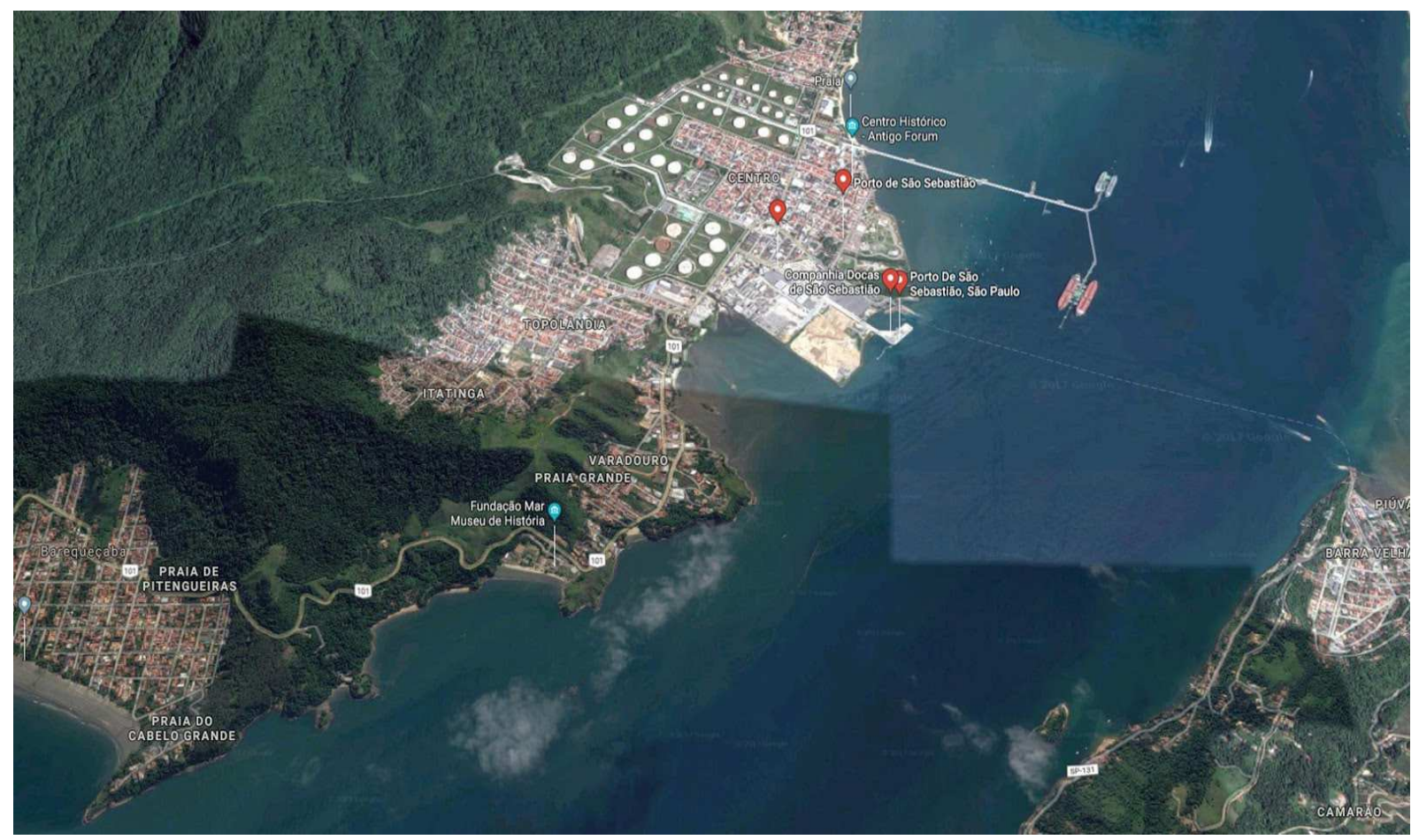

FIGURA 1 - Localização do Porto de São Sebastião, no litoral norte de São Paulo. FONTE: Google maps. 
de n. 1.34.014.000121/2013-91, com o objetivo de "apurar a regularidade ambiental do processo de ampliação do Porto de São Sebastião" (Ministério Público Federal e Do Estado de São Paulo, 2010). Posteriormente, a suspensão de audiências públicas também evidenciou as disputas e as tensões que emergiam entre os diferentes atores envolvidos no processo.

A princípio, o IBAMA marcou uma única audiência no município de São Sebastião. Menos de um mês depois, o Ministério Público Federal questionou a não realização de audiências também em Caraguatatuba, Ubatuba e Ilhabela. Dias depois, o IBAMA convocou a população para uma segunda audiência em Ilhabela. Um dia antes da primeira das duas audiências, o órgão acatou um pedido de suspensão de ambas, formulado por outros dois atores envolvidos no conflito: o Instituto Ilhabela Sustentável e a Secretaria de Transportes do Estado de São Paulo (esta em documento assinado pelo Secretário de Transportes, à época também presidente do Conselho de Administração da CDSS).

Cabe ressaltar que o Instituto Ilhabela Sustentável não pediu a suspensão das audiências somente no processo administrativo do licenciamento. A ONG ambientalista se associou a outras duas ONGs (Onda Verde e Educa Brasil) para fazer o mesmo pedido em um processo judicial. Essa demanda judicial fazia diversos pleitos, incluindo a declaração de nulidade de todo o licenciamento, ou, caso o juiz assim não entendesse cabível, a suspensão das audiências públicas designadas. Os argumentos do processo pouco mencionavam os impactos sociais e ambientais da obra, visto que a ação se propunha apenas a comprovar irregularidades formais no processo de licenciamento, com o fim de suspendê-lo e refazê-lo. Nessa ação, as ONGs pleiteavam a não concessão da licença de ampliação até a regularização da licença de operação das instalações já existentes do porto; a condenação do IBAMA à elaboração de Termo de Referência, com base no Plano de Desenvolvimento de Zoneamento; a comprovação de pagamento de taxas de controle e fiscalização ambiental pretéritas pela CDSS; a comprovação da regularidade do cadastro técnico federal dos profissionais envolvidos na elaboração do EIA/RIMA; a realização de audiências públicas em outros municípios da região, com a devida publicidade; e a condenação a dar maior publicidade ao licenciamento ambiental.

Uma tentativa mais formalizada de abrir diálogo aconteceu em julho de 2011, quando a CDSS e o IBAMA buscaram pela primeira vez o Comitê de Promoção de Diálogo para a Sustentabilidade (COMDIAL) como espaço de aproximação da sociedade civil para discutir o meio ambiente e a economia no litoral norte. O COMDIAL é integrado por ONGs ambientalistas do litoral norte, a Petrobras e a Unisantos, que buscam avaliar conjuntamente os impactos ambientais de grandes projetos planejados para a região nos próximos anos, a exemplo da ampliação portuária.

\subsection{Audiências públicas e adoção do discurso jurídico}

A fase posterior ao processo de licenciamento incluiu a realização de audiências públicas, que possibilitaram a interação de diversos atores sociais em um espaço institucionalizado, evidenciando movimentos de aglutinação e desagregação (Feital, 2014; 2016). No geral, as audiências reprisaram a maioria das discussões que ocorreram antes delas. 
Assim, enquanto a CDSS defendia a ampliação do porto, apoiando-se em aspectos técnicos, científicos ou econômicos, outros stakeholders tendiam a contestar esses argumentos, como as ONGs ambientalistas, uma parcela do setor turístico e do público em geral, o prefeito de Ilhabela e o secretário de Meio Ambiente de São Sebastião. Diversos temas que não correspondiam à finalidade oficial da audiência pública, que é a de oportunizar uma discussão pública sobre o EIA/RIMA e os impactos socioambientais do projeto, também foram abordados nas audiências.

Para Feital (2014; 2016), que fez amplo estudo sobre essas audiências públicas, uma estratégia adotada pelos participantes foi a adoção do discurso jurídico para conferir maior autoridade aos seus argumentos. O Instituto Ilhabela Sustentável se valeu da mesma estratégia e, posteriormente, contratou um escritório de advocacia para produzir um documento para o processo administrativo de licenciamento, identificado como Estudo Contestatório ao EIA/RIMA do Plano Integrado Porto-Cidade (Carvalho, 2016). Respaldando-se em teses jurídicas, esse estudo fez diversas críticas técnicas e ambientais ao EIA/RIMA. Entre as supostas omissões dos estudos de impacto ambiental de expansão portuária, o documento aludiu à necessidade de aprofundar a análise dos impactos cumulativos e sinérgicos, considerando as demais atividades econômicas existentes ou previstas para a região.

\subsection{A atuação do Ministério Público}

Após as audiências públicas, uma nova fase do licenciamento foi inaugurada, evidenciando os contornos políticos e sociais do conflito. Nessa fase, o IBAMA, o órgão licenciador, solicitou esclarecimentos adicionais, analisou documentos exigidos pela legislação e, ao final, emitiu o parecer técnico conclusivo que embasou a análise da primeira autorização. Em dezembro de 2013, o IBAMA concedeu a licença prévia, que atestou a viabilidade ambiental e locacional das fases 1 e 2 do empreendimento. Com a emissão da licença, membros do Ministério Público Federal e Estadual encaminharam uma "Recomendação"5 ao IBAMA, a qual incluía 223 considerações sobre o empreendimento e solicitava a suspensão da licença prévia pelo órgão licenciador. O texto ainda sinalizava que a omissão do IBAMA poderia levar o Ministério Público ao "manejo de todas as medidas administrativas e ações judiciais cabíveis, em sua máxima extensão..."6.

No documento, o Ministério Público manifestou a intenção de que o licenciamento aprofundasse a análise da soma e da interação dos impactos do porto com os impactos dos demais empreendimentos existentes ou previstos para a região. Ao final da "Recomendação", reportou-se novamente ao parecer da equipe técnica multidisciplinar do Ministério Público do Estado de São Paulo: o EIA/ RIMA ainda não havia demonstrado a viabilidade ambiental do empreendimento. Uma vez que a concessão da licença prévia se presta, entre outras

\footnotetext{
${ }^{5}$ ALei Orgânica Nacional do Ministério Público prevê que, no exercício de suas atribuições, incumbe à instituição emitir "recomendações" dirigidas aos poderes públicos e entidades que exerçam funções delegadas pelo Estado ou executem serviço de relevância pública. As recomendações podem ser acompanhadas de requisição ao destinatário, de divulgação adequada e imediata de seu conteúdo, assim como resposta por escrito. ${ }^{6}$ Disponível em: <http://www.mpsp.mp.br/portal/page/portal/noticias/noticia?id_noticia=11291148\&id_grupo=118>.
} 
funções, a atestar essa viabilidade, o Ministério Público recomendou a suspensão da autorização. Como o IBAMA não acatou o pedido do Ministério Público, cinco meses depois, apenas desta vez, o pedido foi reiterado perante a Justiça Federal de Caraguatatuba.

Em maio de 2014, a Procuradoria da República e o Ministério Público do Estado de São Paulo assinaram uma ação judicial para postular, em caráter imediato e provisório, a suspensão do procedimento administrativo de licenciamento e, em caráter final e definitivo, a declaração de nulidade da licença prévia e o compromisso do IBAMA de não emitir uma nova licença enquanto o EIA/RIMA não fosse complementado com os diversos tópicos apontados. Os argumentos judiciais do Ministério Público foram semelhantes aos desenvolvidos em sua anterior "Recomendação" de suspensão da licença enviada ao IBAMA. Prevaleceram os questionamentos aos impactos sociais e ambientais da obra, mas também foram feitas alegações de vícios formais no processo de licenciamento.

O corpo jurídico do IBAMA rebateu um a um os argumentos da ação. No entanto, um mês depois, no final de junho de 2014, a Justiça Federal acatou o pleito imediato e provisório do Ministério Público, suspendendo os efeitos da licença prévia. A decisão ainda impôs outro efeito relevante: os dois réus - IBAMA e CDSS - deveriam incorporar ao EIA/RIMA a análise dos impactos cumulativos e sinérgicos entre as ampliações do porto e do TEBAR (Terminal Almirante Barroso da Petrobrás) ${ }^{7}$, a fim de demonstrar objetivamente a compatibilidade entre os dois empreendimentos. Além disso, exigiu a comprovação de anuência ao licenciamento de quatro gestores de unidades de conservação e obrigou a apresentação de alternativas construtivas menos impactantes no manguezal do Araçá, com a devida justificativa técnico-científica.

Sem que o Ministério Público pedisse, a decisão liminar trouxe uma iniciativa não prevista na legislação que rege a ação civil pública: o juiz designou uma audiência preliminar de conciliação entre as partes do processo. Enfatizando a complexidade do conflito, ele ressaltou a importância de se criar um espaço institucional para as partes buscarem o entendimento. Ainda menos comum foi o local eleito para a realização dessa audiência: a Delegacia da Capitania dos Portos de São Sebastião, situada em frente ao Porto Público. Na decisão liminar, a escolha de um local fora do ambiente forense foi justificada pela possibilidade de uma visita técnica ao empreendimento. Contudo, no dia da audiência conciliatória, o juiz afirmou que a medida também objetivava incentivar a maior participação popular. De fato, os principais atores sociais do conflito compareceram à ocasião, inclusive as ONGs e os demais interessados que não faziam parte do litígio aberto pelo Ministério Público. Das partes interessadas no processo, somente o IBAMA não compareceu. Outras iniciativas espontâneas do juiz ocorreram durante o processo, como a visita técnica ao mangue do Araçá e uma segunda audiência conciliatória em novembro de 2014 (sem a presença do órgão ambiental).

A despeito dos esforços do juiz de aproximar as partes e criar um ambiente para o diálogo, na movimentação documental, autores e réus re-

${ }^{7}$ O TEBAR é operado pela TRANSPETRO, uma empresa subsidiária da PETROBRAS, integra o complexo logístico chamado Porto Público Organizado e responde pela maior movimentação de petróleo na América Latina (Carvalho, 2016). 
correram a diferentes meios para contestarem os argumentos contrários. Apesar de a licença prévia ter sido judicialmente suspensa desde a concessão da medida liminar, o Tribunal Regional Federal alterou as razões e os fundamentos do juiz federal de Caraguatatuba para manter o embargo ${ }^{8}$. Em termos práticos, o licenciamento foi paralisado com a liminar, após o julgamento dos Agravos de Instrumento o Tribunal, e foram redefinidas as exigências aos réus no tocante às complementações que deveriam ocorrer no EIA/RIMA.

Na sentença que viria a ser disponibilizada no Diário Oficial da União em abril de 2016, o juiz invalidou o procedimento que resultou na licença prévia e condicionou a eventual concessão de nova licença prévia pelo IBAMA à complementação do EIA-RIMA pelo CDSS, exigindo que esses estudos prevejam, no mínimo, a devida análise aprofundada dos seguintes tópicos: a-) alternativas locacionais e tecnológicas que afastem a intervenção no manguezal do Araçá; b-) impactos cumulativos e sinergéticos com os demais megaempreendimentos em curso no litoral norte, no tocante às vias de acesso terrestre ao Porto de São Sebastião, ao uso e à ocupação do solo, à habitação e ao saneamento básico.

Conforme o último andamento verificado no processo, em abril de 2017 ainda pendia a apreciação de um recurso de embargos de declaração interposto pelo IBAMA em face da sentença de mérito. Nessa mesma ocasião, o juiz admitiu o ingresso da Fazenda do Estado de São Paulo no processo, como assistente litisconsorcial da CDSS, bem como indagou às partes a respeito da proposta de acordo apresentada pela CDSS.

\section{Resultados da pesquisa}

\subsection{Complexidade de interesses e compreensão dos impactos do empreendimento}

Os documentos analisados e as narrativas colhidas nas entrevistas realizadas apontaram que a resistência ao empreendimento emerge e ganha força com o temor de futuros impactos sociais e ambientais no litoral norte paulista. O representante do Ministério Público, por exemplo, declarou-se preocupado com o empreendimento, principalmente por ser um vetor de futuras ocupações irregulares. Já o representante do Instituto Ilhabela Sustentável enfatizou o aumento do trânsito em uma região já saturada pelo crescimento turístico, enquanto o representante do Instituto Educa Brasil aludiu à relação do porto com a cidade, que ficaria "estremecida" depois das obras.

A pesquisa documental revelou outros receios manifestados na mídia, em audiências, em eventos extraoficiais, em movimentos sociais e manifestações populares, como capacidade de suporte hídrico, destinação de resíduos sólidos, poluição atmosférica, violência urbana e perda dos serviços ecossistêmicos do mangue. Questões estéticas, paisagísticas e de tráfego marítimo também foram suscitadas nas entrevistas para justificar uma oposição específica aos contêineres, apesar de não serem as causas mais prioritárias da resistência. Além da degradação cênica do canal marítimo, as narrativas sinalizaram a preocupação com a convivência dos 
esportes náuticos com grandes embarcações, o receio de colisões e de navios da estatura de prédios barrando o fluxo de vento no canal, e as ameaças a interesses individuais, com a imposição, aos moradores e frequentadores da região, do ônus de uma demanda que não é deles, com perda da qualidade de vida e desvalorização imobiliária.

Renn (1992), em seu clássico trabalho sobre arena de risco (risk arena), argumenta que, ao se analisar os principais atores e suas ações e estratégias em uma arena conformada, sobretudo, pelos riscos envoltos a um empreendimento ou evento, é possível observar que certos conflitos que emergem podem não ser sobre - ou exclusivamente sobre tais riscos, ao revelarem preocupações com outros temas icônicos associados ao debate. Nessa perspectiva, a arena funciona como uma metáfora para descrever a localização simbólica de ações políticas que influenciam as decisões coletivas, em que grupos sociais tentam maximizar sua oportunidade de influenciar o resultado do processo de decisão coletiva por meio da mobilização de recursos sociais (políticos, financeiros, científicos, culturais e humanos) (Ferreira et al., 2017; Hannigan, 2006; Renn, 1992). Tendo isso em vista, a análise do material coletado nesta pesquisa permite sinalizar que, nesta arena (a do licenciamento ambiental), os atores envolvidos buscaram mobilizar diferentes recursos para expressarem seus interesses e suas preocupações e influenciarem o processo decisório.

As ONGs, por exemplo, comunicaram-se entre si e buscaram parcerias técnicas com pesquisadores. Um escritório de advocacia foi acionado e financiado por proprietários de residências no litoral norte paulista, que se alinharam aos objetivos dessas organizações. Da mesma forma, o Ministério Público buscou parcerias técnicas, consultou órgãos públicos, ouviu as ONGs e se aproximou da sociedade civil.

\subsection{Entraves na construção de negociações}

A análise dos resultados permitiu identificar um conjunto de variáveis que, direta e indiretamente, pesou na dificuldade em construir soluções negociadas: as estratégias de comunicação estabelecidas entre os grupos, a ausência de outros atores estatais relevantes, o papel do IBAMA na mediação do conflito e a participação pública antes do licenciamento ambiental. Cada uma dessas variáveis é apresentada e discutida a seguir.

\subsubsection{Estratégias de comunicação}

As estratégias de comunicação, bem como os recursos financeiros, são ferramentas importantes de persuasão nas arenas decisórias e podem ser usadas para atrair indivíduos para determinadas causas. Além dessas ferramentas, o conhecimento científico é outro recurso que pode ser utilizado com esse fim, por meio da mobilização de experts que ofereçam evidências científicas que colaborem com as causas postuladas (Renn, 1992). No caso estudado, algumas ONGs não ignoraram essas premissas teóricas e as adotaram de maneira estratégica. Para além de estratégias de comunicação, o movimento ambientalista, por exemplo, aproximou-se de veranistas e os convenceu a colaborarem financeiramente para a causa da resistência, mediante contratação de peritos especialistas. Várias alianças foram feitas entre ONGs, comunidade científica e Ministério Público, e um escritório de advocacia e uma consultoria ambiental foram acionados para contestar o empreendimento. 
O recurso da comunicação foi mobilizado para a obtenção de outros recursos (financeiros, científicos, judiciais e midiáticos), por meio de uma proposta clara: vencer os argumentos do lado oposto. Nesse ambiente de confronto de ideias, o conflito nasceu da aversão aos impactos de uma obra. Contudo, os ânimos se acirraram diante da dificuldade, por parte dos principais atores, de oferecer soluções para serem negociadas. As narrativas dos entrevistados revelaram que os protagonistas do conflito até se aproximaram; no entanto, a comunicação entre eles foi truncada, o que resultou em uma insatisfação generalizada.

Os dados colhidos evidenciaram que os principais atores do conflito adotaram um discurso polarizado, no qual prevaleceu o desejo de falar, mas nem sempre o de ouvir, e menos ainda o de ceder (Carvalho, 2016). É o que Feital (2014) qualificou de "conversa de surdo" no contexto dos debates travados nas audiências públicas do licenciamento portuário.

\subsubsection{Ausência de outros atores públicos relevantes}

A análise da narrativa do representante da CDSS evidenciou que, em sua perspectiva, caberia à sua empresa assumir os ônus decorrentes de seu empreendimento. Para os representantes das ONGs e do Ministério Público, o licenciamento seria a ocasião adequada para exigir do empreendedor a solução de todos os prejuízos, em sua máxima extensão. O representante do IBAMA partilhou dessa mesma noção obrigacional, porém levantou outras reflexões pertinentes: "E quando os impactos socioambientais não são exclusivamente gerados pelo empreendimento? Quem deve solucioná-los? Somente o empreendedor? E seria somente no âmbito do licenciamento que as soluções para esses impactos deveriam ser planejadas e cobradas?".

Na visão do representante do Ministério Público, outros atores deveriam estar presentes na arena do licenciamento portuário, como as secretarias do Estado de São Paulo, particularmente as pastas de Transportes, Planejamento e Meio Ambiente. Na visão do promotor, o empreendimento portuário parte de uma escala de planejamento maior e, por se tratar de um projeto de Estado, as soluções para seus problemas também requerem maior envolvimento da gestão governamental. Na prática, contudo, o caso estudado evidencia que não foi essa a conformação da arena. A União firmou um convênio delegando ao Estado de São Paulo a administração portuária em São Sebastião. O Estado de São Paulo, por sua vez, criou uma sociedade de economia mista, alegando ao Ministério Público não ter como trazer as secretarias de Estado para a discussão do licenciamento. Com isso, nem o Estado nem a União participaram do desenrolar de um conflito que se originou da intenção de ambos.

Ainda que o foco do estudo realizado não tenha sido a análise da capacidade de planejamento e suporte do Estado brasileiro em lidar com os desafios socioambientais da região, presentes ou futuros, é preciso problematizar a narrativa do representante do IBAMA, quando este mencionou que diversos órgãos públicos foram chamados a opinar no licenciamento e, mesmo assim, a municipalidade de São Sebastião, que tinha mecanismos jurídicos para obstruir a concessão das licenças pelo IBAMA, optou por emitir a certidão de uso e ocupação do solo, documento exigido no curso do licenciamento como condição para a emissão da licença prévia e 
que equivale ao ateste municipal acerca da viabilidade do projeto construtivo no local proposto. Nessa perspectiva, ainda que não seja possível argumentar que uma das causas implícitas da judicialização possa ter sido a desconfiança geral de que o Poder Público (municipal, estadual ou federal) não tem condições de enfrentar os problemas da expansão portuária, com ou sem a ajuda do empreendedor, a ausência de outros atores do governo e do efetivo envolvimento destes nas responsabilidades que lhes competem trouxe entraves à construção de soluções negociadas.

\subsubsection{O IBAMA e a mediação do conflito}

A análise dos dados revelou também a ausência de outro ator estatal no licenciamento portuário: o IBAMA. Ainda que esse órgão não tenha se furtado de suas responsabilidades no licenciamento ambiental e que as narrativas colhidas ao longo da pesquisa evidenciem a evolução do papel técnico que exerceu no decorrer do processo administrativo, as narrativas revelaram que o papel de mediar as tensões envolvidas nos licenciamentos de grandes obras não foi exercido. Não há uma lei que estabeleça expressamente o papel do órgão licenciador como mediador oficial dos conflitos oriundos do licenciamento ambiental. Porém, é possível reconhecer que a figura do Estado continua estratégica na condução e na solução dos conflitos sociais (Hobbes, 2008; Locke; 2005; Rousseau, 2011; Habermas, 1995).

Considerando que a Política Nacional do Meio Ambiente, estabelecida pela Lei Federal n. 6.938/1981, determina que o IBAMA é o órgão executor do Sistema Nacional de Meio Ambiente, nos casos de licenciamentos sob sua responsabili- dade, o papel de mediador dos conflitos seria uma decorrência natural. Logo, se o Estado, por meio do IBAMA, deixa de mediar o conflito e ajudar as partes a construírem soluções consensuais, o mesmo Estado, agora por meio do Poder Judiciário, pode ser chamado a impor uma solução definitiva - pelo menos no sentido jurídico de algo julgado, uma vez que, de uma perspectiva sociológica, nem sempre a solução derradeira da Justiça esgota o conflito na sociedade. Como argumenta Vayrynen (1991), o consenso seria uma mera contingência na sociedade, e seria utópica qualquer possibilidade de resolução definitiva dos conflitos.

A análise dos resultados revelou que o IBAMA não assumiu o papel de mediador do conflito da expansão portuária, perspectiva compartilhada pelos atores entrevistados, que narraram as dificuldades para se comunicar com a Diretoria de Licenciamento de Portos, em Brasília. Em geral, os demais atores mencionaram que o corpo decisório do IBAMA teria sido inacessível ao longo do processo, limitando-se a se comunicar por meio de pronunciamentos oficiais. Mesmo quando o órgão ambiental foi obrigado a se aproximar da sociedade, no caso das audiências públicas previstas em lei, a percepção dos entrevistados sobre o IBAMA foi negativa, o que corroborou os resultados obtidos em estudos realizados anteriormente por Viglio (2012) e Feital (2014). Se o enfraquecimento do papel regulatório dos órgãos públicos abre espaços para que outros atores preencham as lacunas deixadas na arena (Renn, 1992), o caso estudado mostra que atores detentores de outros recursos (que não a autoridade legal no licenciamento) se mobilizaram na arena, a fim de ocupar os vácuos de poder. 


\subsubsection{Participação pública}

Os resultados da pesquisa revelaram que houve intensa participação da sociedade durante o licenciamento ambiental. Essa participação pode ser compreendida como fruto de um movimento espontâneo, sem que as autoridades públicas fomentassem espaços formais com esse intuito, com exceção das audiências e da visita técnica ao mangue, ambas abertas pelo juiz do segundo processo quando o conflito já estava em seu estágio sub judice.

Para compreender o contexto de participação, há um dado histórico do planejamento do empreendimento, anterior ao próprio licenciamento, que não pode ser ignorado como causa implícita da judicialização. Quando se postulam licenças para ampliar o modal portuário brasileiro, o licenciamento ambiental entra no ciclo de uma política pública, embora não na área ambiental, e sim na de transportes. Como atesta Frey (2000), o processo de elaboração e implementação de uma política pública passa por diferentes fases, que podem ser divididas em percepção e definição de problemas; agenda-setting; elaboração de programas e decisão, implementação de políticas; avaliação de políticas e eventual correção da ação.

Nesse sentido, no caso do Porto de São Sebastião, o Estado de São Paulo manifestou a intenção de ampliá-lo desde 1998. Nesse mesmo ano, produziu-se um documento chamado Plano Diretor de Desenvolvimento dos Transportes (PDDT), projetado para o horizonte de 2000 a 2020, no qual se previa a construção de um segundo berço de atracação, além de investimentos em terminais, pátios e armazéns do Porto Público de São Sebastião. Na perspectiva de Frey (2000), esse plano corresponde à fase de elaboração de programas e de decisão acerca de políticas públicas a serem futuramente implementadas. Em 2010, quando a CDSS apresentou ao IBAMA seu EIA/RIMA do Plano Integrado Porto-Cidade (PIPC), já se pretendia passar à fase de implementação de uma política pública de transportes, cujos contornos estavam decididos havia mais de uma década. Assim, quando setores sociais do litoral norte paulista começaram a se manifestar no licenciamento, já estavam superadas as fases de formulação e decisão da política de expansão portuária no Estado de São Paulo. Essas definições foram monopolizadas por instâncias técnicas do governo, sem a participação da sociedade, inclusive da parcela mais diretamente afetada por suas consequências. Por essa razão, o licenciamento ressuscitou a discussão sobre decisões tomadas no passado, possivelmente porque esse debate ainda não estava maduro para a sociedade.

Como argumenta Hannigan (2006), os principais construtores do risco ambiental são os experts ou peritos que, ao estabelecerem uma agenda nas arenas decisórias, até podem incluir a contribuição de outros públicos, mas geralmente isso só é feito nas últimas fases de consideração. No caso do porto, a participação popular ocorreu apenas quando já se pretendia executar uma política de transportes.

Embora uma investigação mais específica sobre as razões que levaram a sociedade a se mobilizar somente no final do ciclo da política pública não tenha sido realizada, os achados da pesquisa evidenciaram que foi na fase do licenciamento que o público foi proativo, não aguardando a abertura de espaços oficiais para tentar influenciar a arena decisória. Em relação à premissa de participação espontânea, é importante atentar que, se a legislação brasileira obriga a ampla divulgação do li- 
cenciamento ambiental para a sociedade, a mesma necessidade não recai sobre a fase de formulação e decisão de uma política logística, sobretudo com a finalidade de discutir os aspectos socioambientais envolvidos nessas questões.

Outra possível razão para a participação pública somente no licenciamento portuário, e não em outras esferas políticas, foi abordada em Teixeira (2013), com base na análise das entrevistas realizadas em seu trabalho: a atuação do movimento ambientalista seria motivada por ameaças concretas, a exemplo da iminente construção de uma grande obra. $\mathrm{Na}$ fase de concepção de políticas públicas planejadas para o horizonte de décadas, como é o caso do Plano Diretor de Transportes do Estado de São Paulo, talvez ainda não houvesse esse viés ameaçador, que dispara a mobilização das organizações sociais. Independentemente das razões que levaram à ausência de participação social em momentos anteriores, o resultado prático no licenciamento foi a dificuldade de se chegar a soluções negociadas. Se para a CDSS esta etapa só deveria conferir abertura para a discussão sobre o melhor modo de executar o que já foi decidido, para as ONGs, aquilo que a CDSS já tratava como decidido ainda deveria ser revisto.

\subsection{Crise de identidade do instrumento legal}

Ao analisar os níveis hierárquicos de tomada de decisão do governo federal brasileiro, Teixeira (2013) argumenta que não foi somente a participação popular que aconteceu na fase de execução da política portuária em São Sebastião. A própria pauta das problemáticas ambientais só foi incorporada aos debates neste último degrau decisório. Sem a participação pública e uma discussão ambiental nos níveis políticos mais elevados, o licenciamento ambiental acabou sobrecarregado como ferramenta, exigindo-se do instrumento "mais do que ele, tecnicamente, pode prover" (Teixeira, 2013, p. 232). Como reconhecem Phillipi Jr \& Maglio (2005), no licenciamento ambiental de grandes empreendimentos, as escolhas do projeto e das tecnologias aplicáveis já foram determinadas por políticas, planos e programas decididos anteriormente, sem uma avaliação aprofundada da soma e sinergia de impactos ambientais. Nesse contexto de desenvolvimento de políticas econômicas, apartadas, contudo, das políticas ambientais, questiona-se: afinal, para que serve o licenciamento ambiental?

Do ponto de vista jurídico, a ferramenta do licenciamento não é adequada para o licenciador analisar e decidir sobre planos, programas e políticas setoriais. O máximo que a legislação prevê é a análise sobre a compatibilidade do projeto em relação a políticas, planos e programas já existentes na região (Resolução Conama 01/1986). Nesse sentido, uma discussão possível no licenciamento estudado seria a de adequação do Porto de São Sebastião ao zoneamento ecológico-econômico do litoral norte paulista, instituído pelo Decreto Estadual n. 49.215/2004. A ampliação portuária corresponderia ao projeto, enquanto o decreto seria a política pública ambiental já criada na região.

A expansão portuária em São Sebastião é uma iniciativa do Estado de São Paulo em conjunto com a União. Só essa circunstância já pode confundir a compreensão dos demais atores de que o licenciamento, sob o prisma técnico-jurídico, não é a arena adequada para decidir sobre planos, programas e políticas, sejam estes ambientais e/ou do setor de transportes. Ocorre que a CDSS, em vez de pleitear 
a licença de um projeto, chamou seu empreendimento de Plano Integrado Porto-Cidade, com a justificativa de harmonizar o desenvolvimento da atividade portuária com o desenvolvimento socioambiental de São Sebastião e de evitar, como sinalizou um entrevistado, a fragmentação das obras em diversos licenciamentos, permitindo que as etapas construtivas acompanhassem a real demanda portuária no futuro. Contudo, a novidade (licenciamento de um plano) encontrou entraves até no próprio IBAMA, uma vez que o órgão licencia projetos, valendo-se de uma legislação pensada apenas para projetos. Um exemplo de limitação do conceito seria o prazo máximo de 5 anos que a lei prevê para a licença prévia. Como conciliar a validade quinquenal da autorização se a CDSS estimou um prazo de mais de 20 anos para executar seu Plano Integrado Porto-Cidade?

Além da proposta inovadora (que no fim foi aceita), mesmo que a ampliação portuária fosse tratada como um projeto pela CDSS, o licenciamento ambiental faria emergir, de qualquer modo, diferentes compreensões sobre sua finalidade. Como as narrativas colhidas evidenciaram, para o Ministério Público e as ONGs, a ferramenta possibilita usos que foram desconsiderados pela CDSS e pelo IBAMA, como uma possível avaliação sobre os impactos do porto em relação aos impactos de outros empreendimentos já instalados ou previstos para a região. Para o Ministério Público, a análise do IBAMA deveria ter considerado a soma e a interação dos impactos do porto com os impactos de outros sete empreendimentos de Petróleo \& Gás e com os impactos de outros quatro trechos rodoviários previstos na região. Para conferir legitimidade jurídica a esse pleito, o Ministério Público invocou o artigo $6^{\circ}$, inciso II da Resolução Conama 01/1986, segundo o qual a análise dos impactos ambientais do projeto deve prever suas propriedades cumulativas e sinérgicas. Contudo, a norma não menciona se a cumulatividade e sinergia devem ser estabelecidas entre os vários impactos gerados pelo mesmo projeto, ou se, além destes, devem ser considerados os impactos de outros empreendimentos da mesma região.

Para Phillipi Jr. \& Maglio (2005), a avaliação integrada de impactos regionais não é típica do licenciamento ambiental, e sim de outro instrumento de política ambiental: a Avaliação Ambiental Estratégica (AAE). Esse entendimento é partilhado por outros estudiosos (Sánchez, 2006; Teixeira, 2013). Teixeira (2013) define aAAE como um instrumento de planejamento que mensura, no médio e longo prazos, impactos cumulativos e sinérgicos de políticas, planos, programas e projetos estruturantes. No Brasil, a AAE ainda não foi regulamentada. Nessa perspectiva, o Poder Público não tem a obrigação de realizá-la e, mesmo quando a realiza, nada garante que o fará no tempo e de modo adequados.

No caso estudado, não foram apenas as partes litigantes que manifestaram diferentes compreensões em relação à análise dos impactos cumulativos e sinérgicos no licenciamento: a resposta da Justiça também evidencia a necessidade de critérios legais mais claros. Afora a indefinição sobre a análise desses impactos, o caso suscita outra questão ainda não superada sobre os limites do licenciamento ambiental. Diferentemente de uma atividade de extração de riquezas naturais, que só pode se desenvolver no local onde se encontram essas riquezas, a ampliação da infraestrutura portuária no Brasil permite mais de uma alternativa de localização do novo empreendimento. Diante das múltiplas possibilidades, caberia o uso do licenciamento para definir qual 
a melhor alternativa de expansão portuária, considerando toda a costa do país? Na compreensão do representante do IBAMA entrevistado na pesquisa, a resposta a essa pergunta é negativa. Escorando-se na legislação brasileira, o argumento é de que o objeto de análise do licenciamento não é a definição da melhor política pública de transportes no litoral brasileiro, mas sim a possibilidade de aprovação ambiental de uma proposta, considerando, entre outros aspectos, o local eleito pelo empreendedor. Já na decisão do desembargador do TRF, a licença foi mantida suspensa até que o EIA-RIMA da CDSS abarcasse todas as alternativas de macro e microlocalização do projeto, cotejando-as com a chamada "alternativa zero", ou seja, comparando a proposta da CDSS com a hipótese de não execução do empreendimento. Antes dessa decisão judicial, no seio do próprio licenciamento, o Instituto Ilhabela Sustentável já questionava a decisão política de ampliar a capacidade portuária do Estado de São Paulo em São Sebastião, alegando que isso poderia ser feito em Santos.

$\mathrm{Na}$ análise desses pontos controvertidos e geradores de dúvidas sobre os limites do licenciamento ambiental, é possível ainda pensar a ausência de participação fora do licenciamento como uma causa em potencial para a dificuldade de se construir soluções negociadas, como argumentado anteriormente. Avrtizer \& Costa (2004) e Bohman (1996) advogam que a vontade coletiva se manifesta menos na exclusividade de representantes eleitos (democracia meramente representativa) e mais nos espaços de abertura (democracia participativa), o que requer um amadurecimento da cultura de mediação entre Estado, sociedade civil e sistema político. Na opinião de Fung \& Cohen (2007), os administradores públicos precisam relevar com maior frequência as preocupações e as opiniões dos cidadãos, não obstante as limitações de tempo e de espaço inerentes aos processos de tomada de decisão, e a manutenção mínima da governabilidade. Enquanto a sociedade e as instituições não tiverem a ampla oportunidade de participar das discussões e definições sobre as políticas públicas que as afetam, provavelmente haverá excesso de expectativas sobre o licenciamento, ocasião em que apenas se tenta executar o que o Estado já decidiu.

\section{Considerações finais: há uma tendência à judicialização?}

Medidas como a judicialização, como argumenta Teixeira (2013), não se ajustam às premissas epistemológicas da modernização ecológica, abordagem sociológica que recomenda soluções mais negociadas e menos impositivas na compatibilização do desenvolvimento econômico com a preservação ambiental. Porém, segundo o autor, em uma sociedade desigual em termos de acesso a recursos políticos, como é o caso da brasileira, iniciativas repressivas por vezes se tornam inevitáveis à tutela de direitos ambientais, notadamente quando a proteção do meio ambiente limita o exercício de direitos econômicos. Ao analisar o caso estudado, não há dificuldade de identificar os atores que consideram a judicialização um problema e os que enxergam na medida uma solução. Porém, mesmo entre aqueles que comemoraram o resultado provisório das ações, a judicialização parece ser somente uma estratégia para alcançar os reais propósitos.

Os achados da pesquisa revelaram que o desejo declarado pelas ONGs seria impedir que os impactos socioambientais se consumissem na 
dimensão do empreendimento proposto. O objetivo maior do Ministério Público seria evitar que os impactos negativos da obra ficassem sem o devido tratamento, ou sem a prévia comprovação de que seriam administráveis. Não cabe ao Poder Judiciário avaliar a viabilidade ambiental do empreendimento, considerando o local e as características da proposta. O máximo que está ao seu alcance é o que foi feito durante todo o trâmite da ação: o adiamento da execução das obras, com a exigência de que novos estudos ambientais fossem apresentados.

Contudo, como o caso estudado mostrou, o IBAMA já havia aprovado o empreendimento com base em análises menos robustas do que gostariam outros atores do conflito e, a priori, não parece que a ação judicial tenha levado o licenciador a rever sua posição inicial. Do contrário, o IBAMA não teria esgotado, como vem esgotando, todas as suas possibilidades de se defender no processo. Ademais, as defesas do órgão licenciador parecem ser não mais que tentativas de persuadir a Justiça de que a licença prévia só foi concedida porque existiam fundamentos técnicos e jurídicos.

A menos que o desfecho do processo judicial leve o IBAMA a mudar seu ponto de vista, ou convença a CDSS a desistir de seu plano inicial, a judicialização tende a ser mais um problema que uma solução, inclusive para aqueles que a promoveram. Todavia, como o caso estudado evidencia, ainda que os prejuízos da judicialização existam, o conflito que emergiu em torno da expansão do Porto de São Sebastião é também uma forma de socialização, visto que é no ambiente social de divergências, e não no de convergências, que se reúnem ou modificam grupos, organizações e interesses (Simmel, 1955; 1983; 2006). O estudo evidencia que o conflito em torno do Porto de São Sebastião aglutinou grupos que provavelmente não se aproximariam em tempos de paz e catalisou transformações sociais que provavelmente não ocorreriam sem uma oposição mais firme ao empreendimento. Dialogando com as perspectivas analíticas de Vayrynen (1991) e Simmel $(1955 ; 1983 ; 2006)$ sobre a faceta transformadora do conflito, é possível argumentar que as causas da judicialização do licenciamento portuário trazem também oportunidades de melhoria para outros processos decisórios, dialogando, assim, com outras produções científicas que chegaram a resultados semelhantes, em casos de obras de infraestrutura (Phillipi Jr \& Maglio, 2005; Christmann, 2012; Teixeira, 2013; Feital, 2014; Viglio, 2012).

No entanto, diante de um problema cujas raízes fazem emergir motivações políticas, sociais e jurídicas, não se imagina que a evolução do sistema se esgote em novos manuais de conduta. Embora seja recomendável a elaboração de uma lei geral de licenciamentos que promova maior segurança jurídica, o aperfeiçoamento do tratamento de impactos socioambientais passa por uma maior incorporação do espírito democrático, a fim de qualificar as relações entre Estado, empreendedor, Ministério Público e sociedade civil. Sem abertura política e mantida a omissão de importantes atores, inclusive governamentais, a tendência é de que prevaleça o discurso de embates, em vez de uma agenda de construção coletiva, e um excesso de expectativas sobre o instrumento de licenciamento ambiental. Dada sua incapacidade de responder a todas as demandas que lhe são endereçadas, certamente a curva ascendente da judicialização de licenciamento de grandes obras deverá continuar. 


\section{Agradecimentos}

Agradecemos aos entrevistados da pesquisa realizada e aos pareceristas pelos comentários recebidos.

\section{Referências}

Avritzer, L.; Costa, S. Teoria Crítica, Democracia e Esfera Pública: Concepções e Usos na América Latina. DADOS Revista de Ciências Sociais, 47(4), 703-728, 2004.

Bardin, L. Análise de conteúdo. Lisboa: Edições 70, 1977.

Bohman, J. Public Deliberation: Pluralism, Complexity and Democracy. Cambridge: MIT Press, 1996.

Brasil. Resolução CONAMA $n^{\circ}$ 237, de 19 de dezembro de 1997. Regulamenta aspectos do licenciamento ambiental. 1997.

Carvalho, V. C. F. Judicialização do licenciamento ambiental: estudo sobre as suas motivações no caso do Porto de São Sebastião. São Paulo, Dissertação (Programa de Pós-graduação Ambiente, Saúde e Sustentabilidade) - USP, 2016.

Christmann, L. A. Gestão Compartilhada do Risco no Licenciamento Ambiental do OSX-Estaleiro/SC: Desafios e Possibilidades. Florianópolis, Dissertação (Programa de Pós-graduação em Direito) - UFSC, 2012.

CPEA - Consultoria Paulista De Estudos Ambientais. Plano Integrado Porto-Cidade PIPC: São Sebastião. Relatório de Impacto Ambiental apresentado à Companhia Docas de São Sebastião. Edição revisada e atualizada. São Paulo, 2011.

Deacon, D.; Pickering, M.; Golding, P.; Murdock, G. Researching communications: a practical guide to methods in media and cultural analysis. London: Arnold, 1998.

Duarte, R. Entrevistas em pesquisa qualitativas. Educar, 24, 213-225, 2004.

Feital, M. S. Conflitos e Arenas Decisórias de Grandes Projetos de Infraestrutura: uma discussão do Porto de São Sebastião - São Paulo - BR. Campinas, Dissertação (Mes- trado em Sociologia) - UNICAMP, 2014.

Feital, M. S. Conflitos e Arenas Decisórias de Grandes Projetos de Infraestrutura - Uma Discussão do Porto de São Sebastião - São Paulo - Brasil. Jundiaí: Paco Editorial, 2016.

Ferreira, L. C.; Calvimontes, J.; Di Giulio, G. M.; Viglio, J. E.; Araos, F. Conflictos entre expansión urbana y cobertura vegetal y sus consecuencias para los cambios ambientales globales: Un estudio en el Litoral del Estado de São Paulo, Brasil. In: Ferreira, L. C.; Schmidt, L.; Buendía, M. P.; Calvimontes, J.; Viglio, J. E. (Org). Clima de tensão: Ação humana, biodiversidade e mudanças climáticas. Série UNICAMP ANO 50, Campinas, SP: Editora da Unicamp, 2017, p. 29-54.

Frey, K. Políticas públicas: um debate conceitual e reflexões referentes à prática da análise de políticas públicas no Brasil. Planejamento e Políticas Públicas, 21, 212-259, 2000.

Fung, A.; Cohen, J. Democracia Radical. Trad. Taís Blauth. Política \& Sociedade, 6(11), 221-237, 2007.

Habermas, J. Três modelos normativos de democracia. Lua Nova, 36, 39-53, 1995.

Hannigan, J. A. Environmental sociology - a social construction perspective. London: Routledge, 2006.

Hobbes, T. O Leviatã. São Paulo: Editora Saraiva, 2008.

Locke, J. Dois Tratados sobre o Governo. São Paulo: Martins Editora, 2005.

Ministério Público Federal e Do Estado de São Pau1o. Recomendação no Inquérito Civil Público $n^{\circ}$ 1.34.014.000298/2008-21 da Procuradoria da República em Caraguatatuba/SP e Inquérito Civil Público 07/2012 do GAEMA/Litoral Norte. 2010

Philippi Jr. A.; Maglio I. C. Avaliação de Impacto Ambiental. In: Phillipi Jr, A.; Alves, A.C. (Eds.). Curso Interdisciplinar de Direito Ambiental. Barueri: Manole, 2005.

Renk, M. Percepção de Riscos no Setor Energético: um estudo de caso envolvendo o gasoduto Mexilhão/Petrobras Litoral Norte Paulista. Campinas, Dissertação (Mestrado em Planejamento de Sistemas Energéticos) - UNICAMP, 2010.

Renn, O. The Social Arena Concept of Risk Debates. In: 
Krimsky, S. Golding, D. (Eds.). The Social Theories of Risk. Westport, CT, 1992, p. 179-197.

Rousseau, J. J. Do Contrato Social. São Paulo: Editora Saraiva, 2011.

Sánchez, L. E. Avaliação de impacto ambiental: conceitos e métodos. São Paulo: Editora Oficina de Textos, 2006.

Simmel, G. Questões fundamentais da Sociologia. Rio de Janeiro: Zahar, 2006.

Simmel, G. Sociologia. Organização de Evaristo de Moraes Filho. São Paulo: Ática,1983.
Simmel, G. Conflict. New York: The Free Press, 1955.

Teixeira, L. R. Megaprojetos no Litoral Norte Paulista: O Papel dos Grandes Empreendimentos de Infraestrutura na Transformação Regional. Campinas, Tese (Doutorado em Ambiente e Sociedade) - UNICAMP, 2013.

Väyrynen, R. (Ed.). New directions in Conflict Theory. Conflict resolution and conflict transformation. Newbury Park, CA: Sage Publications, 1991.

Viglio, J. E. Usos sociais e políticos da ciência na definição de riscos e impactos ambientais no setor de petróleo e gás. Campinas, Tese (Doutorado em Ciências Sociais) - UNICAMP, 2012. 